\title{
Time to talk
}

James Moir

This is the Accepted Author's Manuscript of the book chapter:

Moir, J. (2014). Time to talk. In LewandowskaTomaszczyk , B. and Kosecki, K. (eds.) Time and Temporality in Language and Human Experience, pp.73-83.

The final version is available from Peter Lang via: https://doi.org/10.3726/978-3-653-03331-1 


\title{
Time to Talk
}

\author{
James Moir
}

\begin{abstract}
This paper in concerned with the temporal nature of talk within conversation and its relationship with interpreting and understanding what is said. Within the field of conversation analysis (CA) Sacks (1992) urged analysts not to become concerned with how fast interlocutors are thinking as they talk with one another, but instead to focus on what is produced and in what way. This aversion to inferring mental processes has been taken up by analysts interested in examining discursive psychology (DP) through the ways in which discourse is produced in talk in terms of its orientation to psychological concerns (e.g. Edwards \& Potter, 1992). Such an approach shares with $\mathrm{CA}$ an agnostic stance with respect to underlying mental processes as the modus operandi of conversational exchanges.
\end{abstract}

However, this paper seeks to advance the argument that whilst DP had adopted CA as a methodology for its programme, it has strayed away from its focus on procedural possibilities, and instead has treated interlocutors as engaged in operations such as designing and interpreting what is said. In other words, it treats discourse as involving a tacit process which takes time to operate between interlocutors. This, in effect, leaves the conceptual door ajar for a mentalist construal of what people are engaged in doing when the talk to one another.

The paper argues against this approach and instead suggests that much of our communicative conduct does not involve thinking before speaking, or interpreting what another person has said. The temporal nature of routine conversation is such that we act towards one another in terms of the words themselves. There is nothing in the use of words that requires the postulation or tacit acknowledgement that time is required to design and interpret what is said. Instead the argument is advanced that the flow of conversation and its intelligibility for participants, derives from the ability to use and react to language in a criterial fashion through the words themselves. It is the scenic aspect of most discursive practices that is key to understanding the speed of conversational exchanges, not the quickness of an assumed mental apparatus behind the words that are spoken.

\section{Introduction}

One of the most important questions in examining the temporal nature of conversation as it is experienced is the extent to which cognitive operations are involved in actively choosing what is said. For example, in a recent contribution to this question, Gibbs and Van Oden (2012) advance a view of pragmatics based on complexity theory which explains the pragmatic choices speakers make in conversations in terms of multi-dimensional factors. However, whilst this offers a more sophisticated view of the pragmatics of communication it is rooted in a view of human agents as engaged in operating as 'micro-analysts' of their environment and of each other's conduct. In other words, it is based on a cognitivist assumption that people are engaged in communicating and talking with one another in terms of interpreting, decision- 
making, abstracting, aligning, and disambiguating and so on. The extension of these occasional practices to that of what people do in general in conversing with one another is a foundational assumption for those who would wish to examine how people 'think' whilst talking, and specifically how they can select the words they use in the temporal unfolding of conversation. In other words, talking and communicating become a matter of considering what might loosely be thought of as 'the speed of thought'.

However, whilst this approach may be a central issue for psychological approaches to the study of communication, a different and sociologically orientated approach can be found in the field of conversation analysis. The founder of this approach, Harvey Sacks, was concerned with the basic issue of how language can work as something that can be both culturally learnable and publicly understandable. Very early on (in the Spring of 1964) this led to his often quoted caution about researchers using cognitive intuitions:

When people start to analyze social phenomena, if it looks like things occur with the sort of immediacy we find in some of these exchanges, then, if you have to make an elaborate analysis of it - that is to say, show that they did something as involved as some of the things I have proposed - then you figure that they couldn't have thought that fast. I want to suggest that you have to forget that completely. Don't worry about how fast they're thinking. First of all, don't worry about whether they're 'thinking.' Just try to come to terms with how it is that the thing comes off. Because you'll find that they can do these things (Sacks, 1992, vol. I: 11).

This injunction against falling back on assumed mental operations as the generative mechanism for the production of talk-in-interaction led Sacks, and other conversation analysts who were inspired by his approach, to study in detail the mechanisms through which conversations works in terms of its ordered and scenic qualities. The focus on turn-taking and the normative patterns of various actions such as excuses, assessments, invitations, refusals etc., coupled with detailed transcriptions that include features such as pauses, hesitations, vocal pitch etc. showed just how fast people do talk and how they do so within the joint nature of conversational activity.

This conceptualisation of language as a social phenomenon was offered as a way of examining its properties empirically though a defined methodological approach that held up to scrutiny normative patterns of interaction. However, this has more recently been the subject of a more all-encompassing ontological social theory of action proposed by Theodore Schatzki (2001, 2002, 2006, 2010a, 2010b). As Schatzki argues "Human agency must . . . be understood as something contained in practices (i.e., as the performance of doings and sayings that constitute the actions that compose practices)" (Schatzki 2002: 240). By focusing on practices as the locus of sociality in this way, it is argued that everyday conduct is guided, not by intentional action, formal knowledge or conceptual understandings, but rather by routine practices, know-how, tacit knowledge or informal rules, which may be diffuse, indeterminate or unreflective (Turner 1994, 2007). Practices are therefore seen as primarily routine, habitual and normative events that happen, rather than purposive and generative processes. 
Schatzki defines his social ontology as a "site ontology" that identifies practice 'timespaces' as the "site of the social" (Schatzki 2002: 152, 2010: 6). Site refers to the "clearing" in which practices assume their spatial and temporal immanence and indeterminism. Thus whilst he shares with conversation analysis an eschewal of intentional states and cognitive attributes or 'behind the back' social structures as the engine of interaction, his focus on the "indeterminacy of action" is at odds with the latter in terms of its concern with examining regularities in the way that actions are performed As he puts it "I don't see how the feature of human existence called the indeterminacy of action harbours any obvious or implicit implications about the proper or successful organization of human life" (Schatzki 2010b: 504). The theoretical contortions that Schatzki makes regarding the nature of agency are discussed at length in a recent paper by Caldwell (2012) but from he point of view of this paper what is interesting is that the nature of talk in conversation is considered as a matter of practice, quite literally in the sense of being learned through repeated interactions through which tacit understandings are developed. By extension of this argument the temporal dimension to conversation can also be considered as a matter of practice, although Schatzki leaves space for as he see it its largely indeterminate quality. Participation within a practice only takes on a determinate form as it happens.

Is there a middle ground approach, one in which the metaphor of the temporal flow of conversation is guided by something which human agents orientate towards as they speak? Any contender for this approach could not rest upon the idea that conversational time is driven by internal cognitive operations involving interpreting and designing what was said, nor could it rely upon looking to guiding social structures having associated templates for action. Such an approach would therefore need to avoid theoreticism 'down' at the level of mental operation as well as 'up' at the level of over-arching social structures and processes. A candidate for such an approach is known as discursive psychology (e.g. Edwards and Potter, 1992) and it is to this that the next section of the paper turns.

\section{Discursive Psychology}

Although there is now a sizeable body of work in this area the aim of the paper is not to survey this literature but rather to examine its underlying assumption that agency is constructed within various social practices in terms of an orientation towards psychological representations. Agency is conventionally associated with how people think and feel and the way this relates to their actions. In discursive psychology these psychological representations provide the means for varied ways of engaging in social and institutional life and as a means of performing actions and making them accountable. Cognitive references to 'thinking', giving 'reasons', 'knowing' 'interpreting' or 'understanding' are conceptualised as providing publicly accountable criteria for agency. Take for example, references to "thinking things through" or "thinking before acting". These are presented as providing yardsticks for agency with respect to various activities such as making 'decisions' where the person is about to undertake some sort of commitment that involves certain consequences. They provide both the means for ordering people's lives as the basis for agency and a way for others to consider, judge and assess these actions in the way that they are orientated towards in terms of duality of mind and world. 
Cognition is regarded as the element of control and providing a basis for thinking before acting. The affective or emotional element is taken as being spontaneous and representing feelings but which can, nonetheless, be taken as an accountable basis for action. The emotional basis for action can be presented as understandable, as a means for literally moving a person to do something, or indeed for inaction. It is often portrayed as an influence on how people think, where thinking is taken as reasoning and emotion as providing a means of supporting this or as something that skews or bypasses it.

This duality is presented in discursive psychology in terms of, for example, the ways in which emotion discourse can be a flexible and useful means of characterising action. Edwards (1997:170-201) notes emotion discourse can be put to a great variety of uses within a range of social practices due to their flexibility as an accounting resource. For example, they can be contrasted with cognitions in terms of their less deliberative nature; taken as being as understandable and appropriate as regards how any reasonable person would react; characterised as being the outcome of events or in the nature of the person; treated as being kept under the control of a person's reasoning or as reactions that resist control; and presented as the interaction of mental and physiological systems, as natural, or as derived from moral and ethical concerns.

Discursive psychology therefore seeks to respecify psychological phenomena as discursive constructions, orientated to by participants in the course of interactions as part of various social practices. In this project it has adapted the philosophical framework of Austin's speech acts (1962) and Wittgenstein's notion of languagegames (1953/1958). However, given that discursive psychology operates as a viable alternative to mainstream cognitive psychology it adopts an agnostic stance with respect to mental phenomena. It focus is

In terms of its empirical basis, discursive psychology has borrowed heavily from the techniques used in conversation analysis. It therefore attempts to examine features of language use where interlocutors use various discursive devices in order to accomplish actions. However, unlike conversation analysis, it is less concerned with specifying these with respect to the intelligibility and organised temporal nature of interaction but rather focuses instead on how people orientate towards one another on the basis of psychological states and processes as the basis for action. Thus various psychological topics such as memory, attitudes, emotions, decisions etc. are respecified as discursive phenomena of interest. However, discursive psychology also examines conversation analytic type features such as the use of detail in narrative, membership categorisations, identity displays and so on. All of these features are therefore considered as performative with respect to the accomplishment of actions such as justifying, excusing, rationalising, praising etc.

DP therefore involves a position in which it:

"recognizes that there is some substance to the idea of referring to private mental states, though not as the analysts favoured theory of language and mind. [...] The status of reference to internal mental states is not something to be refuted, even though it is conceptually refutable, but rather, studied as a practice within a public form of life. People may sometimes talk as if, or on 
the proposed and oriented-to basis their words are expressing inner thoughts and feelings." (Edwards and Potter 2005, 256).

Studying participants' orientations, either in terms of direct psychological accounting or in terms of orientating towards aspects of an 'inner/outer' dualism is presented in as permitting another level of analysis in term of the study of the orderliness of social action through the rhetorical construction of discourse. It is argued that in this way a major cultural dualism is maintained: taking people's 'outward' accounts and actions and considering these as representations of what they are like 'inside' as thinking and feeling agents. It is stressed in discursive psychological work that this derives from accountability within practices rather than as the result of some sort of inner mental cognitive processing and exchange of representations.

It is suggested that this is part of a wider cultural commonplace, an inner/outer dualism, and which is integral to a range of social practices. The notion of these two separate realms is therefore taken as being a major rhetorical feature that is incorporated into how people interact with one another. It is also argued that this provides a means of trading on notions of sense making as well as the portrayal of people's inner mental states. In other words, there is a cultural imperative to be seen to be intelligible and to be able to convey one's thoughts and feelings in the form of judgements, reasons, and evaluations as the outcome of some kind of mental process. In perceptual-cognitive processing terms it is an input-process-output model.

It is foundational to discursive psychology that this dualism is orientated to in discourse as part of the social practices that people engage in. It is something that people orientate to in terms of how they portray individual attitudes, beliefs, motives, goals, judgements etc. Notice here that orientating to something does not necessarily involve an explicit mention of these psychological terms but rather how people treat each other as if these are germane or at stake. In effect, this orientation is one of a discourse of an intra-psychic world as something that is normatively attended to as a means of accomplishing order within social practices.

The nature of this order is founded upon an orientation to this discourse as related to mental processes in order to account for how matters are perceived and acted upon. In this way events are placed prior to this operation, as having happened and needing to be communicated, to be understood in terms of a response. People are situated amongst events and occurrences and a realm of mental operations that require to be brought together at a given time and place in terms of accountable action. Accounts of actions are presented as part of texts of 'meaning' in which a mental processing system is assumed to be brought to bear upon matters in order to display them as the result of psychological agents who make 'decisions', have feelings, have deliberated on something or other or who account for something in a way that 'makes sense' to others. We can see why a person might act in a particular way given certain circumstances and the way they react to and deal with these.

Those who take up a discursive psychology position argue that it is unhelpful to start from the assumption that such a dualism exists, that there is a psychological system that operates upon an external reality in order to produce rational thought. For one thing such an assumption is not necessarily a cultural universal, and for another 
people themselves do not exclusively make reference to such a dualism in terms of 'sense making' as they engage in various social practices. Discursive psychologists are therefore not saying that it does not exist but rather that for the purpose of studying how people make of use this dualism we need not start from a cognitivist position. Instead they argue that adopting a non-cognitivist approach allows for a focus on is how this inner/outer dualism is pressed into service as part of various social practices where rationality is something that is at stake or germane.

Discursive psychologists also argue that it would also be absurd to begin from a point of doing what is the point of study, that is, how 'reality' and 'mind' are associated in order to do something or other. To take these as givens would be to fall back on 'experiential reality' as a foundational assumption instead of examining what this dualism is used to do. It is argued that the analytic pay-off for this is in terms of achieving a means of dealing with its sheer pervasiveness as a means of accomplishing a range of social practices. Therefore an analytically agnostic stance is taken with regard to the 'inner mind' and 'external reality' and instead epistemologically relativist, or anti-foundationalist, position is adopted. In this way discursive psychology examines how versions of 'reality' are produced as part of what people do, and in particular as related to the production of what counts as an inner psychology as the basis of agency. It is claimed that the significance of such an analytical move allows the focus of study to become how the relationship between 'mind' and 'reality' is not, for most people, some philosophical issue but a rather a practical sociological construction (Edwards and Potter 1992; Edwards 1997; Potter 2003; Potter 1996; te Molder and Potter, 2005).

The construction of an inner/outer dualism in people's accounts presents a world of texts of meaning in which a mental processing system is assumed to be brought to bear upon this material in order to make sense of it, to provoke a reaction in terms of inner thoughts and feelings. In this way it is suggested that the inner/outer dualism is maintained as a pervasive discursive cultural common place: the construction of mind as an active perceptual-cognitive system working on what is beyond it. Such accounting is presented as a matter of public practice as people engage in various forms of social relations that are mediated through different social and organisational practices. The basis for a person's agency has to be intelligible and therefore it is argued that such accounts must attend to this in their construction. In this sense the hearer of such an account is positioned as outside of the person's thinking as another external psychological agent who must in the course of the account employ his or her own inner processes in order know the other's mind.

It is also argued that discourses of inner mental processes are constructed as relevant to a world of outer matters. One suggested technique in which the mind is made relevant is the notion of thinking leading to an outcome such as a decision or the forming of an opinion or judgment. This kind of direction presents the person as a psychological agent in terms of being able to form an independent judgment, as being able to decide matters for themselves. It is therefore argued that the inner/outer dualism is maintained through the construction of accounts based upon a rhetoric of access to the inner nature of people's psychology. This kind of discourse is rooted in the language of 'interpretation', of 'thinking things through' as a means of portraying a psychological individual through notions of points of view, motives and so on. People are also seen to construct accounts in terms of being affected by parrticular 
circumstances that they experience and which becomes an explanation for their actions. This again preserves the inner/outer dichotomy: the outside world that influences the inner nature of the person. The hearer is again positioned as being given access to an inner world; as being let into a series of thought processes as a way building a rational account. This is considered as a normative orientation in how participants co-construct these accounts within different social practices. The upshot of this for the temporal nature of saptes of interaction is that talk is about 'playing out' these orientations within sequences of actions.

\section{The Problem of Construction and Interpretation}

A problem arises for discursive psychology with respect to the construction and interpretation of what is said. In effect it trades on is the implicit imputation of mentalist notions to interlocutors. These are projected into the analysis of discourse as tacit understandings that are oriented towards. Thus whilst mentalism is not the favoured analyst's theory, it is nonetheless presented as a lay theory attended to in discourse. This is then translated into the occasioned use of various psychological discourses. Commonplace idiomatic expressions such as 'thought' or 'feeling', 'mind' are therefore taken as being theoretically loaded and something to be analysed as such. As Sharrock (2009) points out there is nothing in the words used by speakers that requires the introduction of mentalistic conceptions that are related to performative display and interpretation. This raises the issue of how speakers engage in constructing world and mind in the course of their interactions. In other words, the issue of mastering language use is raised in terms of what is said and whether this is designed or not.

The problem with discursive psychology is not that it fails to recognize language as a form of action, but rather that it burdens this with attempts to engage with this through the classical Cartesian lens of an inner/outer dualism. However, the position argued for here is that people should not be thought of as attending to what they, or others say through such a discursive psychological lens, but rather that they are first and foremost engaged in speech acts bound up with doing things through a host of linguistically constituted practices. It is not that people learn to use various linguistic 'devices' within the temporal flow of conversation but rather that they engage in practices that are not separable from speaking. There is no need to conceptualise discourse through the lens of units of analysis; through a division of syntax, semantics and pragmatics. The codification of language use in this way privileges analytical convenience in terms of the imputation of psychological concerns over intelligibility. In Wittgenstein's 'private-language argument' it is clear that the words and expressions we use are related to public or scenic criteria and not what they strand for in terms of some inner state. In this sense our use of language does not, for the most part, involve a mastery of a discursive psychology but rather is learnable by virtue of using as part of various speech acts. The idea that discourse involves attending to inner/outer orientations, that interlocutors attend to what it stands for in terms of some inner state is therefore a non-issue.

Discursive psychology therefore imputes an inner/outer dualism as the basis for how people attend to one another's language use. It is an interpretivist conception of language use that rests on a the view that people are engaged in constructing what they say as well as analysing what others say in terms of knowing how to proceed in 
the temporal nature of the interaction. However, by following Wittgenstein's line of argument, then it can be argued that language use and comprehension do not normally require design, thought or interpretation. Comprehension and understanding can be considered as interactional achievements of proceedings, whilst interpreting what is said is an activity that one engages in. In other words, there is a tendency in discursive psychology to treat people as if they were engaged in taking time (however short) to rhetorically construct their discourse through various 'linguistic devices' or in 'analysing' what was said. However, it can be argued that this is not the case and that for the most part people are engaged in doings things in the world in terms of speech acts rather than treating words as standing for something or other. Intelligibility and the nature of language use are in this sense bound up with speech acts which, in most of their everyday interactions, simply involves getting on and doing it akin to gestural movements rather than engaging in inspecting the basis for what is said with reference to some inner state.

\section{Conclusion: Talk, Time and Turns}

The key to understanding the temporal dimension of talk and what interlocutors are engaged in is to avoid the trap of any such inter-subjective reification of the notion of language as involving communication between minds. A key, proponent of this view is Coulter (2005) who brings to ethnomethodology a Wittgensteinian attention to the logical grammar of concepts, but convincingly argues and demonstrates that conceptual analysis is invaluable in appreciating language use in logico-grammatical terms. Coulter argues, following, Harris (1981) that language and the ability to converse with one another is best thought of in instinctual terms. Now whilst this may imply for some a linkage with behaviourism, it is far from being the case. Indeed it is possible, to think as George Herbert Mead did of language as "a differentiation of gesture, the conduct of no other form can compare with that of man in the abundance of gesture" (Mead, 1910a: 178). As he says in evolutionary terms we have to consider the communicative function of language as arising from prior gestural conduct (Mead, 1934: 17).

What does this mean for the temporal nature of conversation? The foregoing arguments suggest that we cannot conceptualize ordinary everyday language use in terms of designing and interpreting what is said. This would be to fall back on cognitivist assumptions and lead us down the path of considering the speed of thought rather than focusing on the situated practices of conversing with one another through turns at talk. It is easy to slide into such a cognitivist view of language but such a view detracts from considering language use in terms of actions. If we instead focus on actions and, like Mead, consider these as extensions of gestures, then a clue to the temporal nature of conversation may lie in the idea that such gestures are joint social activities. Mead still left open the door for an inter-subjective consideration of language as related to knowing each other's minds, but it is also possible to take an approach to this issue in terms of the words themselves. Language, as Coulter (2010) argues is not a system to be conceptualized in terms of a tripartite division between grammar, syntax and pragmatics but rather is a very much related to logicogrammatical usage in which the words themselves are self-sufficient. There is no need to consider the speed of thought as an index of language use, or to turn to sociostructural determinants as ways of framing of the temporal dimension talk. This is not to say that people never think before they speak, never design what they are about to 
say or do not operate within the time frames of structured organizational forms of interaction. However, these cases are not necessarily the routine pattern of everyday interaction where, for the most part, people are not engaged in 'interpreting', 'designing', 'planning' and so on in the course of the flow of conversing with others. The latter kinds of activities do take place, but when they do they are the subject of procedural patterns that are brought into play in their very doing. Interpreting is not something that is read into an activity from 'outside' but rather is worked at from within where speakers engage in doing this activity and in a reflexive manner with each other.

\section{References}

Austin, J. L. (1962) How to do Things with Words: The William James Lectures delivered at Harvard University in 1955. Ed. J. O. Urmson, Oxford: Clarendon.

Caldwell, R. (2012) Reclaiming Agency, Recovering Change? An Exploration of the Practice Theory of Theodore Schatzki. Journal for the Theory of Social Behaviour 42, 3, 283-303.

Coulter, J. (2005) Language without Mind. In Conversation and Cognition, edited by Hedwig te Molder and Jonathan Potter, 241-259. Cambridge: Cambridge University Press.

Coulter, J. (2010) Reflections on the "Darwin-Descartes" Problem. Journal for the Theory of Social Behaviour 40, 3, 274-288.

Edwards, D (1997) Discourse and Cognition. London: Sage.

Edwards, D., and Potter, J. (1992) Discursive Psychology. London: Sage.

Edwards, D. and Potter J. (2005) "Discursive psychology, mental states and descriptions." In Conversation and Cognition, edited by Hedwig te Molder and Jonathan Potter, 241-259. Cambridge: Cambridge University Press.

Gibbs, R.W. and Van Oden, G. (2012) Pragmatic Choice in Conversation. Topics in Cognitive Science, 4, 7-20.

Harris, R. (1981) The Language Myth. London: Duckworth.

Mead, G. H. (1934). Mind, Self and Society: From the Standpoint of a Social Behaviorist. C. W. Morris, (Ed.). Chicago: The University of Chicago Press.

Mead, G.H. 1910a. What Social Objects Must Psychology Presuppose? The Journal of Philosophy, Psychology, and Scientific Methods, 7, 174-180.

Potter, J. (1996) Representing Reality: Discourse Rhetoric and Social Construction. London: Sage

Potter, J. (2003) "Discursive Psychology: Between Method and Paradigm." Discourse \& Society, 14, 783-794.

Potter, J. and Edwards, D. (2001) "Sociolinguistics, Cognitivism and Discursive Psychology." In Sociolinguistics and Social Theory, edited by Nicholas Coupland.

Schatzki, T. R. (2001) Introduction: Practice theory. In T. R. Schatzki, K. Knorr Cetina, \& E. Von Savigny (Eds.), The practice turn in contemporary theory (pp. 10-23). London/New York: Routledge.

Schatzki, T. R. (2002) The site of the social. A philosophical account of the constitution of social life and change. University Park: Pennsylvania State University Press.

Schatzki, T. R. (2006) The time of activity. Continental Philosophy Review, 39(2), $155-182$. 
Schatzki, T. R. (2010a) The timespace of human activity. New York: Lexington Books.

Schatzki, T. R. (2010b). Pippin's Hegel on action. Inquiry, 53(5), 409-505.

te Molder, H. and Potter, J. (2005) Conversation and Cognition. Cambridge: Cambridge University Press.

Sacks, H. (1992). Lectures on conversation. Vols. I \& II, edited by G. Jefferson. Oxford: Basil Blackwell.

Sharrock, W. (2009) "Closet Cartesianism in Discursive Psychology." In Against Theory of Mind, edited by Ivan Leuder and Alan Costall, 191-208, Basingstoke, Hampshire: Palgrave MacMillan.

Turner, S. (1994). The social theory of practice: Tradition, tacit knowledge and presuppositions. Cambridge: Polity Press.

Turner, S. (2007). Practice then and now. Human Affairs, 17(2), 110-125.

Wittgenstein, L. (1953 /1958) Philosophical Investigations. Oxford: Blackwell.

James Moir is Senior Lecturer in Sociology at the University of Abertay Dundee, Dundee, Scotland, U.K. E-mail: j.moir@abertay.ac.uk 